\title{
Bioequivalence study of two formulations of bisoprolol fumarate film-coated tablets in healthy subjects
}

This article was published in the following Dove Press journal:

Drug Design, Development and Therapy

29 October 2012

Number of times this article has been viewed

\section{Raymond R Tjandrawinata' \\ Effi Setiawati ${ }^{2}$ \\ Danang Agung Yunaidi ${ }^{2}$ \\ Iwan Dwi Santoso 2 \\ Arini Setiawati ${ }^{3}$ \\ Liana W Susanto' \\ 'Dexa Laboratories of Biomolecular Sciences (DLBS), Cikarang, Indonesia; ${ }^{2}$ Bioavailability and Bioequivalence Laboratory, Equilab International, Jakarta, Indonesia; ${ }^{3}$ Department of Pharmacology and Therapeutics, University of Indonesia, Jakarta, Indonesia}

Background: The present study was conducted to compare the bioavailability of two bisoprolol fumarate $5 \mathrm{mg}$ film-coated tablet formulations (test and reference formulations).

Patients and methods: This study was a randomized, single-blind, two-period, two-sequence crossover study that included 18 healthy adult male and female subjects under fasting condition. The pharmacokinetic parameters were determined based on the concentrations of bisoprolol (CAS 66722-44-9), using ultraperformance liquid chromatography with a tandem mass spectrometer detector. In each of the two study periods (separated by a washout of 1 week) a single dose of test or reference product was administered. The pharmacokinetic parameters assessed were area under the plasma concentration-time curve from time zero to 48 hours $\left(A U C_{t}\right), A U C$ from time zero to infinity $\left(\mathrm{AUC}_{\mathrm{inf}}\right)$, the peak plasma concentration of the drug $\left(\mathrm{C}_{\max }\right)$, time needed to achieve $\mathrm{C}_{\max }\left(\mathrm{t}_{\max }\right)$, and the elimination half-life $\left(\mathrm{t}_{1 / 2}\right)$.

Results: The geometric mean ratios (90\% confidence intervals) of the test drug/reference drug for bisoprolol were 101.61\% (96.14\%-107.38\%) for $\mathrm{AUC}_{\mathrm{t}}, 101.31 \%(95.66 \%-107.29 \%)$ for $\mathrm{AUC}_{\text {inf }}$, and $100.28 \%(93.90 \%-107.09 \%)$ for $\mathrm{C}_{\max }$. The differences between the test and reference drug products for bisoprolol $\mathrm{t}_{\max }$ and $\mathrm{t}_{1 / 2}$ values were not statistically significant $(P>0.05)$. There was no adverse event encountered during this bioequivalence test. The $90 \%$ confidence intervals of the test/reference $\mathrm{AUC}$ ratio and $\mathrm{C}_{\text {max }}$ ratio of bisoprolol were within the acceptance range for bioequivalence.

Conclusion: It was concluded that the two bisoprolol film-coated tablet formulations (the test and reference products) were bioequivalent in terms of the rate and extent of absorption.

Keywords: $\beta 1$-adrenergic receptor antagonist, antihypertension, bioavailability, bioequivalence, bisoprolol, pharmacokinetics

\section{Introduction}

Bisoprolol (CAS 66722-44-9) is a synthetic, competitive, adrenoreceptor antagonist that blocks catecholamine stimulation of $\beta 1$-adrenergic receptors in the heart (cardioselective) and vascular smooth muscle, resulting in a reduction of heart rate, cardiac output, systolic and diastolic blood pressure, and possibly reflex orthostatic hypotension. This effect may be used to reduce workload on the heart and hence oxygen demands, so that the drug is indicated for secondary prevention of myocardial infarction, adjunctive therapy in patients with stable chronic heart failure, and for the treatment of hypertension and angina pectoris. ${ }^{1,2}$ In addition, $\beta 1$-selective blockers prevent the release of renin, a hormone produced by the kidneys that causes constriction of blood vessels. Receptor selectivity decreases with daily doses of $20 \mathrm{mg}$ or greater, at which bisoprolol works against $\beta 2$-adrenergic receptors of the lungs and vascular smooth muscle. Unlike propranolol
Correspondence: Raymond R

Tjandrawinata

Dexa Laboratories of Biomolecular

Sciences, Dexa Medica Group, Industri

Selatan V, Block PP no 7 ,

Kawasan Industri Jababeka II,

Cikarang 17550, Indonesia

Tel +62218984 190I

Fax +622189841905

Email raymond@dexa-medica.com 
and pindolol, bisoprolol does not exhibit membrane-stabilizing or sympathomimetic activity. Bisoprolol possesses a single chiral center and is administered as a racemic mixture. Only the $S(-)$ enantiomer exhibits significant $\beta$-blocking activity. ${ }^{1}$ In oral formulations, bisoprolol, which has a structural formula described in Figure 1, is given as bisoprolol fumarate or bisoprolol hemifumarate $\left(\left[\mathrm{C}_{18} \mathrm{H}_{31} \mathrm{NO}_{4}\right]_{2} \cdot \mathrm{C}_{4} \mathrm{H}_{4} \mathrm{O}_{4}\right.$, molecular weight of 766.98). ${ }^{3}$

Following oral administration, bisoprolol is almost completely absorbed and undergoes minimal first-pass metabolism (less than 20\%), resulting in an oral biovailability of about $90 \%$. The plasma protein binding is approximately $30 \%$, with distribution volume of $3.5 \mathrm{~L} / \mathrm{kg}$. Mean peak plasma concentration $\left(\mathrm{C}_{\max }\right)$ values range from $16 \mathrm{ng} / \mathrm{mL}$ at $5 \mathrm{mg}$ doses to $70 \mathrm{ng} / \mathrm{mL}$ at $20 \mathrm{mg}$ doses; this occurs within 2-4 hours with 5-20 mg dose of bisoprolol fumarate. The plasma elimination half-life $\left(t_{1 / 2}\right)$ is 9-12 hours, resulting in a 24-hour duration of action after once-daily dosing. The kinetics of bisoprolol are linear and independent of age. The pharmacokinetic characteristics of the two enantiomers are similar. Bisoprolol is excreted by renal and nonrenal pathways, of which $50 \%$ is metabolized primarily by CYP3A4 in liver to three inactive metabolites. Metabolism of the drug by CYP2D6 is not clinically significant. The known metabolites are labile and have no known pharmacologic activity. Approximately half of the administered dose is excreted unchanged in urine. Less than $2 \%$ of the dose is excreted in the feces. ${ }^{1-3}$

The present study evaluated the bioavailability of two different oral bisoprolol film-coated tablet formulations following single dosing in healthy adult subjects in order to prove the bioequivalence between both preparations. For a drug to be considered bioequivalent to the reference drug, the area under plasma concentration-time curve (AUC) and $\mathrm{C}_{\max }$ of the drug should be within $80 \%-125 \%$ of the AUC and $\mathrm{C}_{\max }$ of the reference drug. ${ }^{4,5}$

\section{Materials and methods}

\section{Subjects and study design}

This randomized, single-blind, two-period, two-sequence crossover study involved 18 healthy subjects under fasting condition with a 1-week washout period. Eligibility assessments

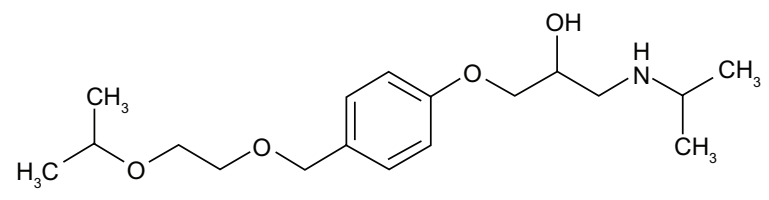

Figure I Chemical structure of bisoprolol (CAS 66722-44-9). ${ }^{3}$ were conducted at the time of screening, within 2 weeks prior to their first dosing day, and were based on physical examination, vital signs (blood pressure, pulse/heart rate, respiratory rate, and temperature), electrocardiography, and laboratory values of liver function (alkaline phosphatase, alanine aminotransferase, aspartate aminotransferase, and bilirubin), renal function (serum creatinine and ureum), hematology (hemoglobin, leukocyte, and platelet count), blood glucose, urinalysis ( $\mathrm{pH}$, glucose, protein, and urine sediment), and seroimmunology (HBsAg, anti-HCV, and anti-HIV). Pregnancy tests (for women) were performed just before taking the drug in each period.

The inclusion criteria were healthy subjects aged between 18 and 55 years at screening, with body weight within normal range (body mass index between 18 and $25 \mathrm{~kg} / \mathrm{m}^{2}$ ), who had signed the informed consent; whilst the exclusion criteria were pregnant women, nursing mothers, women of childbearing potential without adequate contraception, subjects with known contraindication or hypersensitivity to bisoprolol, chronic gastrointestinal problems, liver dysfunction, abnormal hematology with clinical significance, renal insufficiency, and positive test results for $\mathrm{HBsAg}$, anti-HCV, and/or anti-HIV, history of anaphylaxis or angioedema, any bleeding or coagulation disorders, or history of drug or alcohol abuse within 12 months prior to screening.

This study was carried out in accordance with the Declaration of Helsinki, ${ }^{6}$ Good Clinical Practice, ${ }^{7}$ and Good Laboratory Practice. ${ }^{8}$ The protocol, the consent form, and the patient information sheet were reviewed and approved by an independent ethics committee of the medical faculty, University of Indonesia, prior to the study. Written informed consent from all study subjects was obtained prior to any trial-related activities, and the investigator retained the consent forms.

The test preparation (bisoprolol fumarate $5 \mathrm{mg}$ filmcoated tablets, batch no 2300316) was manufactured by PT Ferron Par Pharmaceuticals (Tangerang, Indonesia). The reference preparation (bisoprolol hemifumarate $5 \mathrm{mg}$ filmcoated tablets, batch no L044136) was the innovator product (Concor $5 \mathrm{mg}$; Merck Indonesia, Jakarta, Indonesia) and purchased from the local pharmacy.

\section{Treatment phase and blood sampling}

Subjects attended Equilab International, Jakarta, the night before drug administration and they were requested to fast from any food and drink except mineral water from $9 \mathrm{pm}$. In the morning (approximately $6 \mathrm{am}$ ) of the dosing day 
(day 1), after an overnight fast, a predose pharmacokinetic blood sample was taken. Right afterwards, the study drug (one film-coated tablet of the test drug or the reference drug) was given at 7 am with $200 \mathrm{~mL}$ water.

The date and the time of taking each sample were recorded. Lunch and dinner were provided 4 hours and 10 hours after drug administration, respectively. The amount of food and water intake and physical activity for each individual subject were standardized during the sampling days. Xanthine-containing food or beverages and fruit juices were not allowed for 24 hours before and during the entire sampling days.

From each subject, venous blood samples $(10 \mathrm{~mL})$ were drawn immediately before taking the drug (control), and $5 \mathrm{~mL}$ each at $0.5,1,1.5,2,2.5,3,4,5,7,9,12,18,24,36$, and 48 hours after dosing. One week after the first dosing (ie, washout period), the same procedure was repeated with the alternate drug. The blood samples collected at each time point from all subjects were centrifuged at $4000 \mathrm{rpm}$ for 15 minutes to separate the plasma, and then the plasma was transferred to a clean tube. All plasma samples were stored at $\leq-20^{\circ} \mathrm{C}$ until assayed. The date and time of taking each sample were recorded in the case report forms.

\section{Analysis of drug concentration Method of analysis}

The plasma concentrations of bisoprolol were assayed using a thoroughly validated ultraperformance liquid chromatography with tandem mass spectrometer detector method (UPLC-MS/MS, Acquity UPLC-TQD; Waters, Milford, MA), with respect to adequate sensitivity, specificity, linearity, recovery, accuracy, and precision, both within and between days. ${ }^{9,10}$ The following data were taken from our validation report. The standard calibration curve of bisoprolol ranged from 0.41 to $50.89 \mathrm{ng} / \mathrm{mL}$; linear relationship between concentration and signal intensity were obtained (correlation coefficient, $r=0.9999$ ), and the limit of quantitation was $0.41 \mathrm{ng} / \mathrm{mL}$; precision values by intra-assay coefficient of variation were $7.82 \%, 1.70 \%$, and $2.85 \%$ at low $(1.22 \mathrm{ng} / \mathrm{mL})$, medium $(15.27 \mathrm{ng} / \mathrm{mL})$, and high $(40.71 \mathrm{ng} / \mathrm{mL})$ concentrations, respectively; interassay coefficients of variation were $7.33 \%$, $7.63 \%$, and $7.32 \%$ at low, medium, and high concentrations, respectively; accuracy by intra-assay ( $\%$ difference) ranged from $-8.83 \%$ to $+12.30 \%$ for the low concentration, $-2.69 \%$ to $+1.57 \%$ for the medium concentration, and from $-12.33 \%$ to $-5.26 \%$ for the high concentration; interassay values ( $\%$ difference) ranged from $-8.83 \%$ to $+13.18 \%$ for the low concentration, $-13.13 \%$ to $+13.06 \%$ for the medium concentration, and from $-14.82 \%$ to $+8.99 \%$ for the high concentration. In terms of selectivity, the chromatograms showed there were no interfering substances in six blank plasma samples, and the lowest concentration coefficient of variation was $7.87 \%$, with the recovery ranging between $86.14 \%$ to $114.93 \%$; for recovery, the mean concentrations of standard in blank plasma and acetonitrile were not significantly different from the actual values, ranging from $98.15 \%$ to $113.74 \%$ for the low concentration, $96.99 \%$ to $108.60 \%$ for the medium concentration, and $94.68 \%$ to $108.04 \%$ for the high concentration.

Stability of the samples under frozen conditions, at room temperature, and during a freeze-thaw cycle was also determined. Bisoprolol in plasma samples stable at $\leq-20^{\circ} \mathrm{C}$ for 60 days ranged from $-18.66 \%$ to $18.62 \%$ for the low concentration and $86.86 \%$ to $112.26 \%$ for the high concentration; its samples were also stable at room temperature until 6 hours with ranges from $-6.82 \%$ to $13.18 \%$ for the low concentration and $-9.29 \%$ to $2.04 \%$ for the high concentration. The samples were stable in the freeze and thaw process up to three cycles, with ranges from $-10.53 \%$ to $12.01 \%$ for the low concentration and $-8.57 \%$ to $11.23 \%$ for the high concentration, respectively.

\section{Assay procedure}

The procedures described were applied for the extraction of subject samples, calibration, and quality-control standards. Plasma sample was dispensed in an appropriate tube, and then an appropriate solvent was added. The content of the tube was shaken and centrifuged. The organic phase was transferred to another tube, evaporated under nitrogen gas until dryness, reconstituted with an appropriate solvent, vortexed, centrifuged, and injected into the LC-MS/MS system with a suitable condition. Calibration standards, controls, and samples were processed in batches.

The analytical column was Acquity UPLC BEH C18, $1.7 \mu \mathrm{m}, 2.1 \times 50 \mathrm{~mm}$. The mobile phase was formic acid in acetonitrile:ammonium acetate in such a composition so as to obtain the mass transition ion pair value of $326.35>116.2$ for bisoprolol and 272.3 > 147.4 for dextromethorphan (as internal standard), with a flow rate of $0.2 \mathrm{~mL} /$ minute. The instrument automatically injected a $3 \mu \mathrm{L}$ sample into the chromatographic system.

All chromatograms in the same batch were processed automatically by software using the same processing parameters: integration, peak-to-peak amplitude, and peak detection. Manual integration was performed only when necessary. 


\section{Pharmacokinetic evaluation}

The noncompartmental pharmacokinetic analysis method was employed to determine the pharmacokinetic parameters of bisoprolol. $\mathrm{C}_{\max }(\mathrm{ng} / \mathrm{mL})$ and the time to reach $\mathrm{C}_{\max }\left(\mathrm{t}_{\max }\right.$, hours) were obtained directly from the observed data. The AUC from time zero to the last measurable concentration time $\left(\mathrm{AUC}_{\mathrm{t}}\right.$ ) was calculated by the trapezoidal method. The AUC from time zero extrapolated to infinite time $\left(\mathrm{AUC}_{\text {inf }}\right)$ was calculated as $\mathrm{AUC}_{\mathrm{t}}+\mathrm{C}_{\mathrm{t}} / \mathrm{k}_{\mathrm{e}}$, where $\mathrm{C}_{\mathrm{t}}$ is the last quantifiable concentration, and $\mathrm{k}_{\mathrm{e}}$ is the terminal elimination rate constant and was determined by least squares regression analysis during the terminal log-linear phase of the concentration-time curve. The $\mathrm{t}_{1 / 2}$ (hours) was calculated as $0.693 / \mathrm{k}_{\mathrm{e}}$.

\section{Statistical analysis}

EquivTest version 2.0 (Statistical Solutions, Saugus, MA) was used to perform the statistical analyses of $\mathrm{AUC}_{\mathrm{t}}, \mathrm{AUC}_{\mathrm{inf}}$, and $\mathrm{C}_{\max }$ using analysis of variance (ANOVA) after transformation of the data to their logarithmic (ln) values. Using the error variance $\left(S^{2}\right)$ obtained from the ANOVA, the $90 \%$ confidence intervals (CIs) were calculated from the following equation:

$$
90 \% \mathrm{CI}=\left(\bar{X}_{\mathrm{T}}-\bar{X}_{\mathrm{R}}\right)_{0.1(\mathrm{v})} \sqrt{S^{2} x \frac{2}{n}},
$$

where $\bar{X}_{\mathrm{T}}, \bar{X}_{\mathrm{R}}$ are the means of the $\ln$ transformed values for the test product $(\mathrm{T})$ and the reference product $(\mathrm{R}) ; S^{2}$ is the error variance obtained from the ANOVA; $n$ is the number of subjects; $\mathrm{t}_{0.1}$ is the $t$-value for $90 \% \mathrm{CI}$; and $\mathrm{v}$ is the degree of freedom of the error variance from the ANOVA.

The anti-ln of the above CIs were the $90 \% \mathrm{Cls}$ of the ratios of the test to the reference geometric means.
The power of study was $80 \%$ with 0.05 alpha $(\alpha)$. The acceptance criteria for bioequivalence were that the $90 \% \mathrm{Cls}$ of the geometric mean ratios were $0.80-1.25$ for the AUC and $\mathrm{C}_{\max }$. The $\mathrm{t}_{\max }$ difference was analyzed nonparametrically on the original data using the Wilcoxon matched-pairs test. The $t_{1 / 2}$ difference was analyzed using Student's paired $t$-test.

\section{Results}

All subjects were healthy Indonesians, had normal values of all clinical as well as laboratory parameters measured, and were compliant with the inclusion/exclusion criteria of the study. Blood samples pertaining to a total of 18 subjects (16 male and two female), 20-42 years old, with body mass indices between 18.78 and $24.77 \mathrm{~kg} / \mathrm{m}^{2}$, were analyzed for pharmacokinetic evaluation of bisoprolol.

The profiles of mean plasma concentrations versus time in subjects $(n=18)$ after oral administration of $5 \mathrm{mg}$ bisoprolol fumarate film-coated tablets of the test drug and reference drug are displayed in Figure 2. The values of pharmacokinetic parameters $\left(\mathrm{AUC}_{\mathrm{t}}, \mathrm{AUC}_{\mathrm{inf}}, \mathrm{C}_{\max }, \mathrm{t}_{1 / 2}\right.$ and $\left.\mathrm{t}_{\max }\right)$ and the geometric mean ratios $(90 \% \mathrm{CI})$ of $\mathrm{AUC}_{\mathrm{t}}, \mathrm{AUC}_{\mathrm{inf}}$, and $\mathrm{C}_{\max }$ of bisoprolol results from the test drug as well as the reference drug are presented in Table 1.

\section{Discussion}

The aim of the present randomized, single-blind, two-period, two-sequence crossover study under fasting conditions with 1-week washout period was to compare the bioavailability of the test formulation of bisoprolol fumarate $5 \mathrm{mg}$ immediaterelease film-coated tablets with that of the reference formulation. The advantage of providing scientifically sound

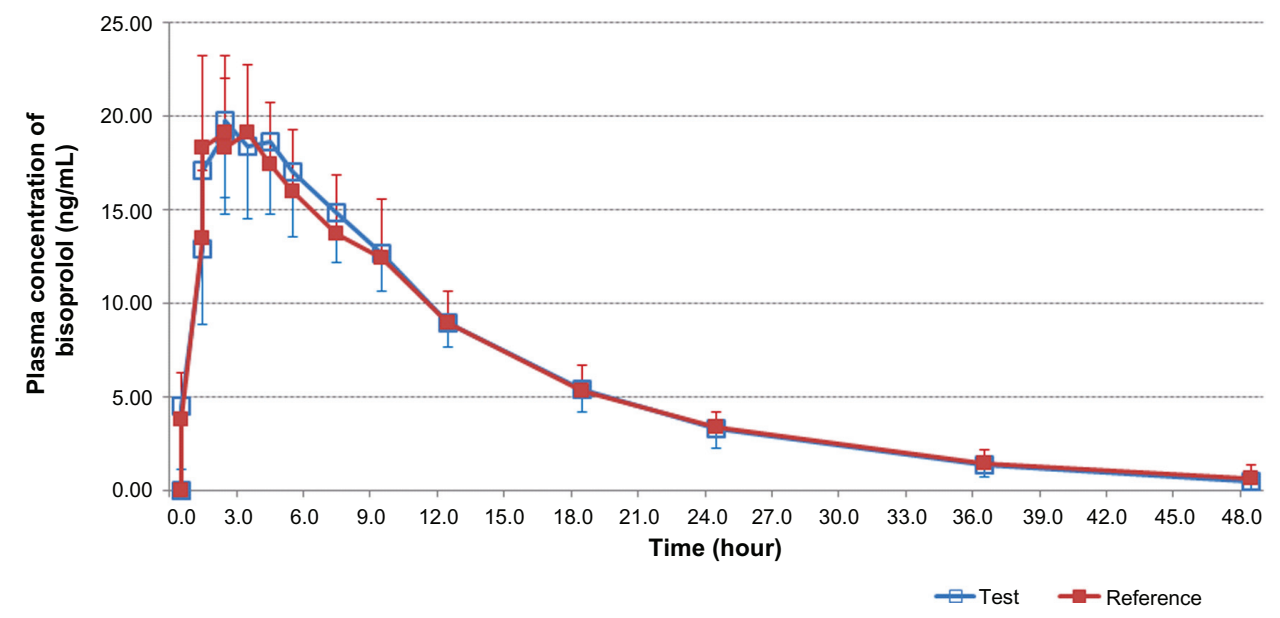

Figure 2 Mean plasma concentrations versus time profiles of bisoprolol in human subjects $(n=18)$ after single-dose oral administration of 5 mg bisoprolol fumarate filmcoated tablet of the test drug and the reference drug. 
Table I Pharmacokinetic parameters and statistical comparison of bisoprolol after single-dose oral administration of $5 \mathrm{mg}$ bisoprolol fumarate film-coated tablet of the test $(T)$ and the reference $(R)$ drug $(n=18)$

\begin{tabular}{|c|c|c|c|c|}
\hline \multirow[t]{2}{*}{ Parameter } & \multicolumn{2}{|l|}{ Mean (SD) } & \multirow{2}{*}{$\begin{array}{l}\text { Geometric mean ratio } \\
\text { of } T / R(90 \% \mathrm{Cl})\end{array}$} & \multirow[t]{2}{*}{$\% \mathbf{C V}$} \\
\hline & Test product & Reference & & \\
\hline $\mathrm{AUC}_{\mathrm{t}}$ (ng.hour/mL) & 275.91 (48.58) & $272.51(55.22)$ & $101.61 \%(96.14 \%-107.38 \%)$ & $9.49 \%$ \\
\hline $\mathrm{AUC}_{\text {inf }}(\mathrm{ng} \cdot \mathrm{hour} / \mathrm{mL})$ & $287.13(51.54)$ & $284.93(61.58)$ & $101.31 \%(95.66 \%-107.29 \%)$ & $9.85 \%$ \\
\hline $\mathrm{C}_{\max }(\mathrm{ng} / \mathrm{mL})$ & $20.7 \mid(4.14)$ & $20.67(4.03)$ & $100.28 \%(93.90 \%-107.09 \%)$ & $11.27 \%$ \\
\hline$t_{1 / 2}(h)$ & $9.05(2.29)$ & $9.11(1.71)$ & $N S^{b}$ & - \\
\hline $\mathrm{t}_{\max }(\mathrm{h})^{\mathrm{a}}$ & $2.00(1.50-4.00)$ & $2.00(1.50-3.00)$ & $\mathrm{NS}^{\mathrm{c}}$ & - \\
\hline
\end{tabular}

Notes: aValues expressed as median (range); 'banalysis performed by Wilcoxon matched-pair test; 'analysis performed by Student's paired $t$-test. Statistical calculations for AUC, and $\mathrm{C}_{\max }$ were based on In-transformed data. Bioequivalence criteria are defined as $90 \% \mathrm{Cl}$ of the geometric mean ratios of T/R of between $80.0 \%$ and I25.0\% for $A \cup C_{t}, A \cup C_{\text {inf }}$ and $C_{\text {max }}$.

Abbreviations: $\mathrm{Cl}$, confidence interval; $\mathrm{CV}$, coefficient of variance; $\mathrm{h}$, hours; SD, standard deviation; NS, not significant; $\mathrm{AUC}$, area under the plasma concentration-time curve from time zero to 48 hours; $A \cup C_{\text {inf }} A U C$ from time zero to infinity; $C_{\max }$, peak plasma concentration of the drug; $t_{\max }$, time needed to achieve $C_{\max } ; t_{1 / 2}$, elimination half-life.

evidence that the test formulation, or the so-called generic product, is bioequivalent to the reference (which is usually the innovator's product) is that the bioequivalent generic product can be used interchangeably with the reference, yet definitely is available at a more affordable price than the reference. This has made generic products much more accessible to patients in need.

The absorption of bisoprolol is not affected by food. The film-coated tablets of bisoprolol fumarate $5 \mathrm{mg}$ were administered to overnight fasting subjects in order to eliminate any pharmacokinetic interactions between food and drug, including the influence of food on drug absorption. ${ }^{4,5}$ The pharmacokinetic parameters of $5 \mathrm{mg}$ bisoprolol fumarate film-coated tablets were assessed based on the plasma concentrations of bisoprolol.

In order to perform the two one-sided test procedures for bioequivalence on log-transformed data of plasma concentration of bisoprolol, with bioequivalence limits of 0.80 and 1.25 for $\mathrm{AUC}$ and $\mathrm{C}_{\max }, \alpha=0.05$ and power $=80 \%$, the number of subjects needed for the bioequivalence study was determined by means of CIs, as formerly presented by Diletti et al. ${ }^{11}$ In the present study, the intrasubject coefficient of variance obtained from the ANOVA for the bisoprolol $\mathrm{AUC}_{\mathrm{t}}$ was $9.49 \%$ (Table 1). Hence, the number of subjects in this study (18 subjects) ensured adequate power to confirm a statistical conclusion.

Healthy subjects were selected under the eligibility criteria, which were set to ensure that only subjects without accompanying diseases that could interfere with the conduct and scientific evaluation of the study were enrolled in the study. Additionally, involving healthy subjects only minimized risk to the subjects' well-being.

In this study, $\mathrm{AUC}_{\mathrm{t}}, \mathrm{AUC}_{\text {inf }}$, and $\mathrm{C}_{\text {max }}$ of bisoprolol were defined as the main parameters in order to assess possible bioequivalence between both preparations. Based on standard bioequivalence guidelines, the criteria for bioequivalence are the $90 \% \mathrm{CI}$ of the test/reference geometric means ratio in the range of $80.00 \%$ to $125.00 \%$ for both $\mathrm{AUC}$ and $\mathrm{C}_{\max }$. The results of the present study showed that the geometric mean ratios $\left(90 \% \mathrm{CIs}\right.$ ) of $\mathrm{AUC}_{\mathrm{t}}, \mathrm{AUCi}_{\mathrm{nf}}$, and $\mathrm{C}_{\text {max }}$ of bisoprolol were $101.61 \%$ (96.14\%-107.38\%), 101.31\% (95.66\%-107.29\%), and $100.28 \%$ (93.90\%-107.09\%), respectively. The $90 \%$ CIs of the test/reference ratios for $\mathrm{AUC}_{\mathrm{t}}, \mathrm{AUC}_{\mathrm{inf}}$, and $\mathrm{C}_{\max }$ of bisoprolol were within the acceptance range for bioequivalence.

In each subject, the $\mathrm{AUC}_{\mathrm{t}} / \mathrm{AUC}_{\mathrm{inf}}$ ratio of bisoprolol was above $80 \%$ (90.70\%-98.68\% for the test drug and $87.96 \%-$ $98.07 \%$ for the reference), indicating that the sampling time was sufficiently long to ensure an adequate description of the absorption phase.

The mean (standard deviation) $t_{1 / 2}$ of bisoprolol for the test drug was 9.05 (2.29) hours and for the reference was 9.11 (1.71) hours. These values were within the bisoprolol $t_{1 / 2}$ based on the literature, which is about $9.00-12.00$ hours. ${ }^{1,2}$ Utilizing Student's paired $t$-test, the $t_{1 / 2}$ values of the test and the reference drug were not significantly different, demonstrating a comparable rate of drug elimination from the body.

The results obtained for median (range) of $\mathrm{t}_{\text {max }}$ of the test drug was $2.00(1.50-4.00)$ hours and $2.00(1.50-3.00)$ hours for the reference drug. Using the Wilcoxon matched-pairs test on the original data, the difference between the $t_{\text {max }}$ values of the two drugs (test and reference drug) was not statistically significant.

There were no dropouts in this study. Nor were there any adverse events encountered.

\section{Conclusion}

Based on the pharmacokinetics and results of this study, it was concluded that the two formulations of bisoprolol fumarate $5 \mathrm{mg}$ film-coated tablets were bioequivalent in terms of the rate and extent of absorption. 


\section{Acknowledgments}

We deeply thank the volunteers for their participation in this study. The assistance of Putuwitia Pramihadarini, Pharm, in preparing the study report is gratefully appreciated.

\section{Disclosure}

The authors declare no competing interests in connection with the contents of this manuscript.

\section{References}

1. Lancaster SG, Sorkin EM. Bisoprolol. A preliminary review of its pharmacodynamic and pharmacokinetic properties, and therapeutic efficacy in hypertension and angina pectoris. Drugs. 1988;36(3):256-285.

2. Concor ${ }^{\circledR} 5$ and Concor $^{\circledR} 10$ film-coated tablets [package insert]. Available from: http://home.intekom.com/pharm/merckp/concor.html. Accessed July 27, 2012.

3. Sweetman SC. Martindale: The Complete Drug Reference. 36th ed. New York: Pharmaceutical Press; 2009:1234.

4. The European Agency for the Evaluation of Medicinal Products (EMA), Committee for Proprietary Medicinal Products (CPMP). Note for Guidance on the Investigation of Bioavailability and Bioequivalence. Available from: http://www.ema.europa.eu/docs/en_GB/document_ library/Scientific_guideline/2009/09/WC500003519.pdf. Accessed September 26, 2012.
5. Badan Pengawas Obat dan Makanan Republik Indonesia (BPOM RI). Pedoman Uji Bioekuivalensi [Indonesian Guideline for Bioequivalence Studies]. Jakarta: BPOM; 2004.

6. World Medical Association. Declaration of Helsinki. Recommendations Guiding Physicians in Biomedical Research Involving Human Patients. Amended by the 52nd WMA General Assembly, Edinburgh, Scotland; 2000 .

7. International Conference on Harmonisation (ICH) Expert Working Group. ICH Harmonized Tripartite Guideline. Guideline for Good Clinical Practice E6 (R1). Geneva: ICH; 1996.

8. Organization for Economic Co-operation and Development (OECD). OECD Series on Principles of Good Laboratory Practice and Compliance Monitoring. Number 1: OECD Principles on Good Laboratory Practice. Paris: OECD; 1997.

9. Bhatt J, Subbaiah G, Kambli S, et al. A high throughput and sensitive liquid chromatography-tandem mass spectrometry (LC-MS/MS) method for the estimation of bisoprolol in human plasma using multiplexing technique. J Chromatogr B Analyt Technol Biomed Life Sci. 2007;852(1-2):374-381.

10. Gabriela P, Corneliu O, Aurel V. Experimental research for determination of bisoprolol fumarate in human plasma samples using liquid chromatographytandem mass spectrometry (LC-MS/MS) technique. Rom Biotechnol Lett. 2010;15(2):5140-5145.

11. Diletti E, Hauschke D, Steinijans VW. Sample size determination for bioequivalence assessment by means of confidence intervals. Int J Clin Pharmacol Ther Toxicol. 1991;29(1):1-8.
Drug Design, Development and Therapy

\section{Publish your work in this journal}

Drug Design, Development and Therapy is an international, peerreviewed open-access journal that spans the spectrum of drug design and development through to clinical applications. Clinical outcomes, patient safety, and programs for the development and effective, safe, and sustained use of medicines are a feature of the journal, which

\section{Dovepress}

has also been accepted for indexing on PubMed Central. The manuscript management system is completely online and includes a very quick and fair peer-review system, which is all easy to use. Visit http://www.dovepress.com/testimonials.php to read real quotes from published authors. 